\title{
Sustaining Physics Teacher Education Coalition programs in physics teacher education
}

\author{
Rachel E. Scherr \\ Department of Physics, Seattle Pacific University, Seattle, Washington 98115, USA \\ Monica Plisch and Renee Michelle Goertzen \\ Department of Education and Diversity, American Physical Society, College Park, Maryland 20740, USA
}

(Received 26 April 2016; published 27 February 2017)

\begin{abstract}
Understanding the mechanisms of increasing the number of physics teachers educated per year at institutions with thriving physics teacher preparation programs may inspire and support other institutions in building thriving programs of their own. The Physics Teacher Education Coalition (PhysTEC), led by the American Physical Society (APS) and the American Association of Physics Teachers (AAPT), has supported transformation of physics teacher preparation programs at a number of institutions around the country for over a decade. In 2012-2013, PhysTEC supported an independent study on the sustainability of its sites after project funding ends. The study sought to measure the extent to which programs have been sustained and to identify what features should be prioritized for building sustainable physics teacher preparation programs. Most of the studied sites have sustained increases in the number of physics teachers educated per year as well as funding for physics teacher preparation. About half of the programs are thriving, in that in the post-award period, they have further increased both the number of physics teachers educated per year and funding for physics teacher preparation. All studied sites that sustained increases in the number of physics teachers educated per year have two features in common: a champion of physics teacher education and institutional commitment. The thriving physics teacher preparation programs in this study implemented different elements of physics teacher preparation according to diverse local priorities and opportunities, including the unique expertise of local personnel.
\end{abstract}

DOI: 10.1103/PhysRevPhysEducRes.13.010111

\section{INTRODUCTION}

The Physics Teacher Education Coalition (PhysTEC) project has directly supported over 40 institutions to build model programs to educate future physics teachers, and has established a coalition of more than 300 institutions committed to improving physics teacher education [1]. PhysTEC-supported sites have collectively more than doubled the number of graduates per year from their physics teacher preparation programs. To put this in perspective, if all 760 institutions that grant a physics degree collectively doubled the number of well-prepared physics teachers per year, this would substantially address the national need for new physics teachers [2].

The PhysTEC project funds sites for a limited number of years [3], after which the host institution is expected to sustain the program. The success of PhysTEC sites rests not only on increasing the number of graduates per year prepared to teach physics; it is equally important to sustain these increases over time, as well as increase the quality of the programs in which physics teachers are educated.

Published by the American Physical Society under the terms of the Creative Commons Attribution 3.0 License. Further distribution of this work must maintain attribution to the author(s) and the published article's title, journal citation, and DOI.
In 2012, we embarked on a formal study to investigate the sustainability of PhysTEC programs. The primary research questions are as follows:

(1) Are PhysTEC legacy sites [4] sustaining an increase in the number of physics teachers educated per year?

(2) Did the PhysTEC award precipitate long-term support for physics teacher preparation at the legacy sites?

(3) What features should be prioritized for building sustainable physics teacher preparation programs in the PhysTEC model?

In what follows, we identify the features that are common to all studied sites that sustained increased numbers of physics teachers educated per year. These two features are (i) a champion of physics teacher education and (ii) institutional commitment. Only one studied site lacks this pair of features, and that site discontinued its teacher education program. We then document features of thriving PhysTEC programs, and illustrate the variety of ways that different institutions have successfully cultivated these features within their programs. Our purpose is to inspire and support institutions in building thriving physics teacher preparation programs of their own by sharing the mechanisms of physics teacher preparation at other successful institutions using the PhysTEC model. The full results of this study are presented in the report Sustaining 
Programs in Physics Teacher Education, available at phystec.org/sustainability [5].

In this paper we describe the PhysTEC model of teacher preparation (Sec. II), then the study design (Sec. III). We identify which PhysTEC legacy sites have sustained their physics teacher preparation programs (Sec. IV) and describe the two common features of sustained physics teacher preparation programs in detail (Sec. V). We provide examples of the diverse means by which thriving programs have implemented the PhysTEC model and sustained large increases in the number of physics teachers educated per year (Sec. VI). We conclude with implications for current physics teacher preparation programs.

\section{THE PHYSTEC MODEL OF TEACHER PREPARATION}

Literature on teacher preparation programs identifies five broad domains of important program features: (i) program purpose, (ii) requirements for subject-matter knowledge, (iii) requirements for pedagogical and other professional knowledge, (iv) field and clinical experiences, and (v) faculty and staff qualifications [6-10]. PhysTEC focuses on the components of a teacher preparation program that are in the domain of a disciplinary department, and emphasizes strong collaboration with schools of education to address other components. For example, by requiring sites to report their annual numbers of physics teacher graduates, PhysTEC conveys its program purpose (domain i): to address the national physics teacher shortage by supporting sites in producing more highly qualified physics teachers. By defining a "highly qualified" physics teacher as one with a major or minor in physics, PhysTEC supports measurable requirements for subject-matter knowledge (domain ii).

Regarding the other domains (requirements for pedagogical and professional knowledge, field and clinical experiences, and faculty and staff qualifications), there is a widely acknowledged lack of evidence for recommending specific program features [6,9-13]. Instead, there is a call for documented experimentation in teacher education programs: for example, the National Research Council requests a "much clearer and more detailed picture of ... how teacher preparation is delivered, as well as a means of tracking changes in this picture over time," and particularly seeks "descriptive information about programs and pathways" for teacher education [9]. Another source recommends that "school districts, states, and the federal government should continue to experiment with various approaches to teacher recruitment, while collecting data that can be used to improve approaches that are promising and end those that are not" [6]. The purpose of the research represented here is to document sites' successful approaches and discern the features that make them successful.

Literature on physics teacher preparation programs identifies several "key components" needed to build thriving programs [14]. These key components include (1) recognition and support for the departmental teacher education champion, (2) targeted recruitment of preservice physics teachers, (3) active collaboration between physics departments and schools of education, (4) a sequence of courses focused on the learning and teaching of physics, (5) early teaching experiences, (6) individualized advising of teacher candidates by knowledgeable faculty, (7) mentoring by expert physics teachers, and (8) a rich intellectual community for graduates, such as a network of local expert physics teachers. The key components are further explained at the PhysTEC website [15]. PhysTEC requires that every funded site implement each of these key components, in order to stimulate skill building and capacity development in many areas relevant to physics teacher education. During the award period, each site implements each key component in a manner consistent with the local context, taking advantage of institution-specific resources and expertise. After the award period, institutions transition into a more self-determined period, in which they select the key components that they will continue to emphasize.

PhysTEC's approach is distinct from some other widespread approaches to science teacher preparation, and the results of this study should be understood as applying to teacher preparation programs in the PhysTEC model, not teacher preparation programs broadly construed. For example, UTeach, a program to prepare STEM teachers at University of Texas at Austin that has been replicated at over 40 institutions nationwide, focuses on coursework in the school or college of education [16]. PhysTEC, by contrast, focuses on activities in the physics department.

\section{STUDY DESIGN}

In what follows, the terms "site" and "institution" refer to one of the universities participating in the PhysTEC study conducted in 2012-2013. The terms "physics teacher" and "secondary physics teacher" denote a PhysTEC Secondary Graduate: a student who has graduated from a PhysTEC Institution [19], has a major or minor (or equivalent coursework) in physics, and has completed a teacher education program leading to certification.

\section{A. Site selection}

The sites selected for this study meet two criteria: They received awards from PhysTEC to support secondary physics teacher education, and their award period had ended when the study began in 2011 (they were "legacy sites" at that time). Nine sites met these criteria. One site was unavailable to participate in the study due to leave of the site leader. Thus, this study includes the following eight sites:

- University of Arkansas (UArk)

- University of Colorado, Boulder (CU-B)

- Florida International University (FIU) 
- Seattle Pacific University (SPU)

- University of Arizona (UAz)

- Western Michigan University (WMU)

- University of North Carolina-Chapel Hill (UNC)

- Cornell University (Cornell)

The study period for each site extends from three years before that site's PhysTEC award to the spring of 2012. Data about PhysTEC graduates extends one additional year, to spring of 2013, because it was readily available and added information on sustainability.

\section{B. Quantitative data collection}

Quantitative data were collected to document specific activities at each site over the study period, including the number of PhysTEC Secondary Graduates each year, the extent to which specific components of the PhysTEC program at that institution were sustained, the quantity of time that faculty and staff dedicated to physics teacher education, and the quantity of funding for physics teacher education. In order to determine if a site sustained an increase in the number of physics teachers educated per year or funding for physics teacher education, the value of that quantity is compared for the periods before and after the PhysTEC award. For example, to determine whether there is a sustained increase in the number of physics teachers educated per year at a site, the average number of physics teachers graduating in the years since that site's PhysTEC award ended is compared to the average number graduating in the years before the award. This calculation provides a sense of long-term change in the quantity.

To evaluate PhysTEC legacy sites' education of new physics teachers over the long term (the key indicator of a sustained program), PhysTEC regularly collects data on PhysTEC Secondary Graduates from all funded sites. Information about the quantity of personnel time and funding dedicated to physics teacher preparation was initially gathered from in-person interviews with site leaders and other personnel during site visits. (Site visits are described in more detail below.) In order to be as inclusive as possible and learn about all the activities that sites considered important, the study did not initially specify which activities should count as contributing to physics teacher preparation. These interviews generated an extensive catalog of kinds of activities that sites consider relevant to physics teacher preparation, such as recruitment of secondary physics teachers, undergraduate teaching experiences, construction of pathways to become a secondary physics teacher, and creation or maintenance of physics-specific pedagogy classes. The study authors then selected the items in this catalog that are consistent with PhysTEC's vision of physics teacher preparation. For example, PhysTEC no longer supports introductory course transformation with its awards, so introductory course
- Funds salaries for undergraduate early teaching experiences in physics (i.e., physics Learning Assistant programs) in which particip teaching ants are actively recruited into secondary

- Funds scholarships for secondary physics teachers (e.g., through the Robert Noyce Teacher Scholarship Program)

- Funds construction of pathways to become a secondary physics teacher (pays for faculty and staff to design physics teacher certification programs)

- Funds advising of preservice secondary physics teachers (pays for faculty and staff to advise preservice teachers both academically and about being a teacher)

- Funds mentoring and induction of inservice secondary physics teachers

- Funds teaching or professional development of secondary physics teachers (students who have declared a physics teaching major and/or inservice secondary physics teachers)

- Funds creation or maintenance of physics-specific pedagogy classes (such as LA pedagogy courses or science methods courses with specific physics pedagogy content)

- Funds a Teacher Advisory Group of secondary physics teachers (i.e., network of local secondary physics teachers who serve as physics teacher education resources)

- Funds a Teacher in Residence or Visiting Master Teacher (an experienced secondary physics teacher who works part-time or full-time with any aspect of the physics teacher education program)

- Funds the development of resources benefiting secondary physics teacher education (e.g., professional development materials specific to secondary physics teachers, observational assessment instruments for evaluation and support of secondary physics teachers, diagnostic tools to be used by secondary physics teachers with their students)

FIG. 1. Funded activities supporting physics teacher preparation. When only a fraction of an award is dedicated to these activities, only that fraction of the award is counted as supporting physics teacher preparation.

transformation was removed from the catalog of personnel and activities supporting physics teacher preparation, whereas courses primarily serving preservice physics teachers are still consistent with PhysTEC priorities and were retained in the catalog. The resulting catalogs of personnel and activities related to physics teacher preparation provided metrics with which to quantitatively compare activity across sites. (The catalog of program activities is presented in Fig. 1; the catalog of personnel activities is similar.) Site leaders and other personnel were interviewed remotely to document (1) which personnel at each site engaged in each of the activities in the catalog, and what fraction of their time they spent on those specific activities; and (2) which awards to that site funded each of the activities in the catalog, and what fraction of the award funded those specific activities.

\section{Qualitative data collection}

In addition to quantitative data, this study documents the history, development, pressures, opportunities, motivations, and constraints on physics teacher preparation at each site. 
Based on the amount of activity known to be occurring at a given site, five of the eight participating sites (UArk, CU-B, FIU, SPU, and UNC) were selected for comprehensive inperson site visits lasting two or three days. The other three sites (UAz, WMU, and Cornell) were selected for a "remote site visit" consisting of interviews conducted by telephone. Sites with three or more active personnel in physics teacher education were selected for in-person site visits; sites with one or two active personnel were selected for remote interviews. An independent consultant (author Scherr) conducted both kinds of site visits.

Comprehensive visits consisted primarily of interviews with as many different kinds of personnel with a stake in physics teacher preparation as possible, along with observations of courses and facilities relevant to physics teacher education. For example, the site visit to FIU included interviews with the champions (faculty members in physics and education), the chair and the former chair of the physics department, other faculty in physics, the Dean of the College of Arts and Sciences, the Dean of the College of Education, the Associate Director of the School of Integrated Science and Humanities, the Vice Provost, a Teacher in Residence (local physics teacher who helps educate future teachers), the coordinator of the secondary science education program, a graduate student researching physics teacher education, and a number of physics learning assistants. The questions asked at each interview were specific to the interviewee's role in contributing to physics teacher preparation at that site. The goal of these interviews was to document and synthesize the activity contributing to physics teacher preparation at that site (present, past, and anticipated), the different contributions of personnel in different roles supporting physics teacher preparation, the institutional support for physics teacher education, the activities of the champions, and circumstances that promote or inhibit the education of new physics teachers by that site.

Remote site visits consisted of one to three interviews with site personnel (including the champion). These interviews had the same purposes as those described above.

\section{Validation and limitations}

Personnel at the studied sites are the primary source of information reported in this study. PhysTEC's data collection processes verify each site's report of the numbers of PhysTEC Secondary Graduates. Awards supporting physics teacher education were verified to the extent that they are a matter of public record (e.g., awards from the National Science Foundation). Much of what is reported concerns the history, development, constraints, pressures, and opportunities that sites perceive as being important to physics teacher preparation in their local context. The PhysTEC project management team checked reports for accuracy. Further validation is through member checking: Each site checked that the report on its site accurately describes its site's events and conditions.
Limitations on this study include the fact that any study of physics teacher education is necessarily based on a small number of people and events, and conclusions are therefore tentative. Only eight sites were available for participation in this study, with varied institutional contexts. In addition, PhysTEC's own conditions have changed: over the years PhysTEC has decreased the award period (from 5 to 3 years), reduced funding for reforming introductory physics courses, increased expectations for sustainability, and made other changes. For all these reasons, the results of this study should be treated as a preliminary understanding of sustainability in the PhysTEC context.

\section{SUSTAINED AND THRIVING PHYSTEC PROGRAMS IN PHYSICS TEACHER PREPARATION}

\section{A. Increase in the number of highly qualified physics teachers educated per year}

Seven of the eight PhysTEC legacy sites studied have sustained an increase in the number of highly qualified physics teachers educated per year. Four of the eight sites studied have further increased the number of highly qualified physics teachers educated per year beyond the increase during the award period. One site has discontinued its teacher education program. These results suggest that the activities taking place at PhysTEC legacy sites are effective for increasing the number of highly qualified physics teachers educated per year in the long term.

A site is defined as having a "sustained increase" in the number of physics teachers educated per year if the average number of physics teachers educated per year in the postaward period (ending in the spring of 2012) is greater than that in the pre-award period by at least 1.0. An increase of one physics teacher per year is considered substantial in that nearly all institutions graduate fewer than two physics teachers a year, and the most common number of graduates is zero [2]. To sustain an increase in the number of physics teachers educated per year is an achievement: A site with a sustained increase in the number of physics teachers educated per year has typically maintained the increase it achieved during the PhysTEC-funded period of the program.

A site is defined as having "further increased" the number of physics teachers educated per year if the average number of physics teachers educated per year in the postaward period (ending in the spring of 2012) is greater than that in the pre-award period by at least 2.0. To further increase the number of physics teachers educated per year is a high achievement: A site with a further increase in the number of physics teachers educated per year has typically exceeded the increase it achieved during the PhysTECfunded period of the program.

Table I details the results for each studied site. The "preaward average" and "post-award average" are the average number of physics teachers educated per year before and 
TABLE I. Number of physics teachers educated per year at PhysTEC legacy sites over the long term. "Pre-award average," "award average," and "post-award average" are the average number of physics teachers educated per year before, during, and after the PhysTEC award, respectively. "Increase" denotes the amount by which the post-award average exceeds the pre-award average. Teacher preparation status is "sustained" for sites whose increase is at least 1.0, and "further increased" for sites whose increase is at least 2.0.

\begin{tabular}{|c|c|c|c|c|c|}
\hline Institution & Pre-award average & Award average & Post-award average & Increase & Teacher preparation status \\
\hline UArk & 0.3 & 4.3 & 6.0 & 5.7 & Further increased \\
\hline CU-B & 1.0 & 2.0 & 3.2 & 2.2 & Further increased \\
\hline FIU & 0.0 & 1.0 & 2.0 & 2.0 & Further increased \\
\hline SPU & 2.3 & 3.0 & 4.0 & 1.7 & Further increased $^{\mathrm{a}}$ \\
\hline UAz & 0.3 & 2.0 & 1.6 & 1.3 & Sustained increase \\
\hline WMU & 3.7 & 6.4 & 4.8 & 1.1 & Sustained increase \\
\hline UNC & 0.0 & 1.0 & 1.0 & 1.0 & Sustained increase \\
\hline Cornell & 2.0 & 0.5 & 1.0 & -1.0 & Not increased \\
\hline
\end{tabular}

${ }^{\mathrm{a}} \mathrm{SPU}$ is identified as having further increased its number of physics teachers educated per year even though its increase is not quite two per year, because SPU's number of teachers educated per year is close to the threshold for further increase of this number, and follows the trend of other institutions that further increased the number of teachers educated per year in showing an increasing average over the pre-award, award, and post-award periods.

after the PhysTEC award, respectively. The difference between the post-award average and the pre-award average is indicated in the "increase" column. Since the PhysTEC award period is typically 3 to 5 years long and it takes about 1 to 3 years to educate new PhysTEC graduates, this calculation provides a sense of long-term change in the quantity.

\section{B. Increase in funding for physics teacher preparation}

Seven of the eight PhysTEC legacy sites studied have sustained increases in funding for physics teacher preparation. These are the same sites that have sustained increases in the number of physics teachers educated per year. Four of the eight PhysTEC legacy sites studied have sustained large increases in funding for physics teacher preparation. At one site, personnel continue to contribute to physics teacher preparation, but funding has not increased; this site discontinued its physics teacher education program. Stating these results another way: All studied sites that saw increased funding for physics teacher preparation sustained an increase in their number of physics teachers educated per year, and sites with greater funding saw greater increases in the number of physics teachers educated per year over the long term.

Funded activities supporting physics teacher preparation are defined in Fig. 1. Such funding may derive from the institution, from grants by government agencies such as the National Science Foundation, or from other sources. Overall in this study, about $40 \%$ of funding for physics teacher education derives from the institution, about $15 \%$ is PhysTEC funding, and the remainder is from other external sources.

Table II details the results for each studied site. Yearly average funds supporting physics teacher preparation are reported in thousands of dollars for the pre-award period, award period (including PhysTEC funds), and post-award

TABLE II. PhysTEC legacy sites' funding for physics teacher preparation over the long term. "Funding increase" denotes the difference between the average yearly funding in the post-award and the pre-award periods. Funding is reported in thousands of dollars. Institutions whose funding increase is at least $\$ 100,000$ are identified as having "sustained" an increase in funding for physics teacher preparation; institutions whose funding increase is at least $\$ 500,000$ are identified as having "further increased" their funding for physics teacher preparation.

\begin{tabular}{lccccc}
\hline \hline Institution & $\begin{array}{c}\text { Pre-award } \\
\text { funding }(\$ \mathrm{~K})\end{array}$ & $\begin{array}{c}\text { Award-period } \\
\text { funding }(\$ \mathrm{~K})\end{array}$ & $\begin{array}{c}\text { Post-award } \\
\text { funding }(\$ \mathrm{~K})\end{array}$ & $\begin{array}{c}\text { Funding } \\
\text { increase }(\$ \mathrm{~K})\end{array}$ & $\begin{array}{c}\text { Funding } \\
\text { status }\end{array}$ \\
\hline UArk & 20 & 290 & 600 & 580 & Further increased \\
CU-B & 70 & 320 & 570 & 500 & Further increased \\
FIU & 120 & 500 & 770 & 650 & Further increased \\
SPU & 30 & 580 & 1030 & 1000 & Further increased \\
UAz & 40 & 300 & 200 & 160 & Sustained increase \\
WMU & 0 & 190 & 90 & 90 & Sustained increase $^{\text {a }}$ \\
UNC & 30 & 190 & 180 & 150 & Sustained increase \\
Cornell & 160 & 300 & 180 & 20 & Not increased \\
\hline \hline
\end{tabular}

${ }^{\mathrm{a}} \mathrm{WMU}$ is identified as having sustained its increase in funding even though its increase is not quite $\$ 100,000$ per year, because it is very close to the threshold for sustained increase of funding. 
period. "Funding increase" is the difference between the average yearly funding in the post-award period and the average yearly funding in the pre-award period, in thousands of dollars. A site is defined to have "sustained" an increase in funding for physics teacher preparation if the yearly average funding contributing to physics teacher preparation in the post-award period is greater than that in the pre-award period by at least $\$ 100,000$, the yearly amount of a typical PhysTEC award. Three of the studied sites have a funding increase of $\$ 100,000-\$ 200,000$; these sites are considered to have sustained increases in their funding for physics teacher preparation. Four sites have a funding increase of $\$ 500,000$ or more; these sites are defined to have "further increased" their funding for physics teacher preparation.

In this study, funds contributing to physics teacher preparation are those that support the specific activities in Fig. 1. In some cases these activities also benefit all preservice teachers at an institution, or all preservice science teachers, or both inservice and preservice teachers, or preservice physics teachers along with physics undergraduates. In certain cases the activities benefit the undergraduate physics program as a whole (e.g., a learning assistant program). For this reason, it is not appropriate to calculate the institutional cost of educating one physics teacher by dividing the funds contributing to physics teacher preparation by the number of physics teachers educated. Rather, the funding reported benefits the larger physics teacher education program, which in many cases benefits other populations at the same time.

\section{COMMON FEATURES OF SUSTAINED PHYSTEC PROGRAMS}

Seven of the eight PhysTEC legacy sites studied are identified as "sustained" physics teacher preparation programs (UArk, CU-B, FIU, SPU, UAz, WMU, and UNC), in that they have sustained increases in both the number of physics teachers educated per year and the funding for physics teacher preparation. One site has not sustained its physics teacher preparation program (Cornell). In this section, we identify common features of sustained physics teacher preparation programs.

\section{A. First common feature: Champions}

All studied sites have at least one champion, defined as one who secures funding and personnel benefiting physics teacher education and negotiates with the institution for changes beneficial to physics teacher education. In other words, every studied site has at least one person who creates, funds, staffs, and institutionalizes physics teacher education at his or her institution. This suggests that the champion is essential.

This study characterizes champions as those who undertake certain activities, rather than those who are "personally committed to physics teacher education," the characterization adopted by the Task Force on Teacher Education in Physics (T-TEP) [2]. At many of the studied sites, those who lead efforts for physics teacher education do have such personal commitment, which sustains their professional focus on physics teacher education over the long term. At some sites, however, champions have a primary commitment to a broader cause that includes physics teacher education, such as science teacher preparation or STEM education broadly construed. These champions may be effective advocates for physics teacher preparation regardless of its primacy in their intentions.

All champions at the studied sites are faculty, consistent with their activities of securing funding and personnel and negotiating with their institution for changes that benefit physics teacher education. All sites have at least one champion who is a member of the physics faculty, or had such a champion at the time that the physics teacher preparation program was originated. Four of the eight sites studied have, or have had, champions with at least a partial appointment in the College or School of Education. At one site, the champion is currently a non-tenure-track faculty member in the College of Science, but that champion was formerly a physics faculty member, and is still in a role that allows her to conduct all the activities of a champion. Though faculty members-even champions-often contribute only a small fraction of their time to physics teacher education ( 0.1 full-time equivalent is typical), their influence can be substantial.

Champions act at a variety of institutional, regional, and national levels with a variety of different constituencies to advance physics teacher education. The following is a compilation of the activities of the personnel identified as champions at the studied sites. Not all champions studied performed all of these activities, but several champions performed each of the activities listed.

Direct service to physics teachers. - Champions serve physics teachers directly by teaching physics-specific teacher education courses, connecting physics teachers to professional development and outreach opportunities, developing mentoring and induction programs for physics teachers, and leading physics teacher advisory groups. Champions interact with undergraduates by recruiting specific students into physics teacher education, advising students to support them in pursuing physics teaching, and mentoring preservice teachers.

Creation and maintenance of physics teacher preparation programs.-Champions establish and maintain programs that make physics teaching more attractive to, and feasible for, undergraduates. They direct teacher scholarship programs, UTeach replication sites, and other physics (or science) teacher preparation programs. They recruit physics undergraduates into these programs, and pursue funding and hire personnel to support and promote them. 
Departmental leadership benefiting physics teacher education.-Champions serve their department by transforming introductory courses, securing resources for course transformation, establishing and sustaining LA programs, developing programs to bring teaching identity into the physics department, and raising awareness of students and faculty regarding careers in high school teaching. They advise graduate research in physics education. They hire faculty and staff supporting physics teacher education and support other personnel who contribute to physics teacher education. They lead collaborations with other departments to benefit teacher education. They lead departmental committees to increase the number of majors through recruitment into physics teaching. They serve as department chairs, supporting the establishment of physics teacher preparation courses and programs.

Institutional engagement benefiting physics teacher education.-At the institutional level, champions work closely with university administration for mutual benefit. They cultivate strong relationships with administrators, making sure administrators understand the benefit that accrues to their institution through physics teacher education. They serve institutional interests by representing their institution at regional and national events. They secure institutional funding for physics teacher preparation programs, sometimes through institution-wide centers and institutes. They may serve as dean, negotiating faculty lines specifically for physics teacher education and leading efforts to establish physics teacher education in the College of Science or equivalent.

National advocacy for physics teacher education.Champions frequently serve the national professional community as well. They may be nationally recognized for promoting physics teacher education through published studies or invited talks on teacher knowledge and practice. They may serve on national bodies such as the Task Force for Teacher Education in Physics [2]. They may engage in national policy, such as testifying before the U.S. Congress on the state of STEM education at the undergraduate and graduate levels or contributing to the Association of Public and Land-grant Universities' (APLU's) efforts in the Science and Mathematics Teacher Imperative [21].

The fact that all studied sites have at least one champion is partly by selection: PhysTEC awards are made only to sites that have effective leadership for physics teacher education. However, for physics teacher education to be sustainable at a site, the champion must be sustained as well. This sustainability may be attributed to an institution's support for and recognition of the champion (described below), and its commitment to physics teacher education in general.

\section{B. Second common feature: Institutional commitment}

All studied sites that have sustained increases in the number of physics teachers educated per year have substantial institutional commitment to physics teacher education, meaning that the institution supports both the champion(s) and the program. (In what follows, the term "institutional commitment" always refers to internal support of physics teacher education by the university in question; though this support is sometimes strengthened by the champion having obtained external funding, such funding is not "institutional commitment.") The one site at which institutional commitment was greatly reduced discontinued its physics teacher education program. This suggests that institutional commitment is essential. PhysTEC sites are selected partly on the basis of institutional commitment.

Institutional support for the champion(s) is crucial for sustaining the leadership of efforts supporting physics teacher preparation. Institutional support constitutes positive pressure to continue advancing physics teacher preparation. The Report of the Task Force on Teacher Education in Physics [2] observed that in most physics teacher education programs, recognition and support for the champion was "minimal and not commensurate with the amount of work involved." In contrast, this study documents that at sites that have sustained increases in the number of physics teachers educated per year, champions have substantial institutional recognition and support. At various sites this support has included a mandate to pursue physics teacher education as part of one's regular teaching, research, and/or service; tenure, promotion, and salary increases; hiring of STEM education colleagues; establishment of infrastructure supporting physics teacher education (such as a STEM education center or institute); and/or appointment to influential positions (such as director of a center or institute). The PhysTEC award itself may increase support to the champion not only through prestige, but also through site visits from PhysTEC staff, which sites report to be effective for educating administrators about the benefits of supporting physics teacher education.

Institutional commitment to physics teacher education is also evidenced by support for physics teacher education programs. For example, some institutions fund salaries for undergraduate early teaching experiences in physics, such as learning assistant programs; others pay for recruitment activities, or support faculty to engage in advising, mentoring, or instruction of future physics teachers. In a few cases, faculty lines are created and filled for the specific purpose of supporting physics teacher education. Occasionally an institution funds a broad effort, such as an institutional center or institute, whose mission supports physics teacher education. At many institutions, the decision to allocate internal resources to physics teacher education happens at the dean and/or provost level, rather than at the department level. This finding suggests a likely pathway to sustainability at other institutions.

Institutional motivation to support physics teacher education, as observed in this study, may include fulfilling the 


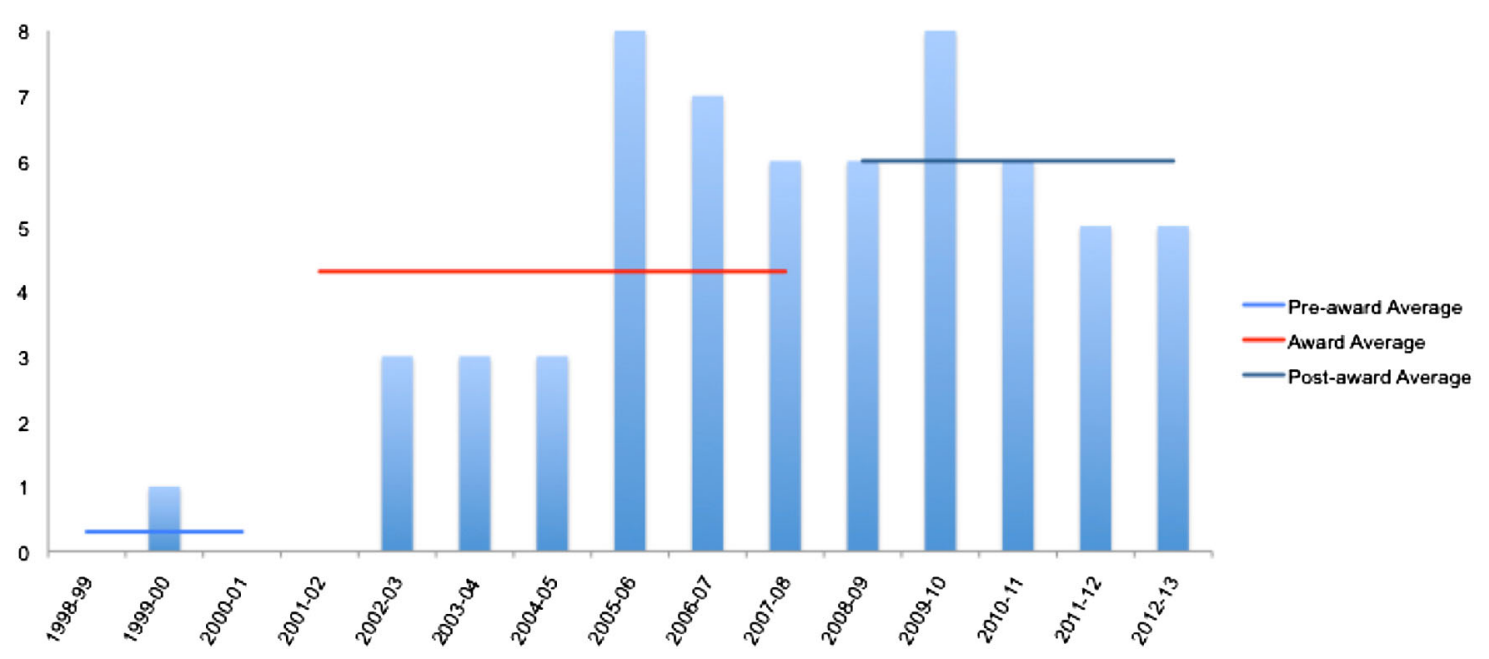

FIG. 2. PhysTEC secondary graduates from the University of Arkansas (UArk).

institutional mission, serving regional needs, improving the reputation of the institution in the community, supporting strong members of the faculty, and being visible on a national stage. These motivations tend to be more apparent at the dean and provost level than within the disciplinary departments. Some specific institutional motivations are described below. In some cases, institutions support physics teacher education as part of a broader effort to improve STEM teacher education; the numbers of prospective physics teachers at an institution may be too small to merit institutional support for their own sake. As a discipline, however, physics sets a strong example for improving STEM teacher education; its history of discipline-based education research and professional society leadership can motivate institutions to support physics teacher education as a model for other disciplines.

\section{DIVERSE FEATURES OF THRIVING PHYSTEC PROGRAMS}

Thriving physics teacher education programs implement PhysTEC key components according to diverse local priorities and opportunities, including the unique expertise of local personnel. In what follows we present case studies of four different PhysTEC legacy sites that have sustained large increases in the number of physics teachers educated per year. For each site we provide an overview of the PhysTEC program and the institutional context in which it is situated; highlight a selected institutional strength and describe how this supports physics teacher preparation and implementation of the key components; and describe the champion and institutional commitment, which are common features of all sustained programs in this study.

\section{A. University of Arkansas}

The University of Arkansas (UArk) is a research university that is working to sustain and increase its research and teaching accomplishments while improving its image in a region that does not necessarily prize academia. Physics teacher education is regarded as a way for the University to serve the community, which encourages institutional buy-in. The average output of PhysTEC secondary graduates increased from near zero before the PhysTEC award to about four per year during the award period (2001-2008; see Fig. 2). In the five years after the award period the average was about six per year. Lessons learned from UArk about sustaining physics teacher education programs in the PhysTEC model are listed in Fig. 3.

\section{Institutional strength: Champion of undergraduate education}

Physics teacher education at UArk during the study period revolved around PhysTEC Site Leader Gay Stewart [22]. Stewart held a physics faculty position with a distinctive mandate: to see that the undergraduate program

- It is possible for an institution to educatesix to eight physics teachers a year over a sustained period.

- In favorable circumstances, a single hardworking faculty member can lead the transformation of physics teaching and physics teacher education at an institution and can sustain that transformation over many years.

- These favorable circumstances include strong relationships between the champion and administrators, and the champion's mandate from the university to devote a significant fraction of time to physics education issues.

- Supporting physics teacher education can solve significant problems faced by institutions, such as improving the institution's image in the community.

FIG. 3. Lessons learned from the University of Arkansas (UArk) about sustaining physics teacher education programs in the PhysTEC model. 
was thriving. Stewart was brought to UArk to address student dissatisfaction with physics teaching at UArk that had grown to strike proportions in the 1990s. She and the rest of the leadership team accomplished this with introductory course transformation, gaining the respect and trust of the students, the department, and the university administration. Stewart formed close advising relationships with many undergraduates. Starting with the PhysTEC award, Stewart used her position with undergraduates, the department, and the administration to create flexible degree programs that allow many different students to become PhysTEC Secondary Graduates. She energetically recruited learning assistants, actively encouraged students to pursue physics teaching, and connected teacher graduates to professional development and outreach opportunities. Through a myriad of day-to-day activities as well as larger, longer-term efforts, Stewart has used her position as a champion of undergraduate education to establish and sustain a thriving physics teacher education program.

The introductory course transformation that Stewart initiated is an important avenue for recruitment. Preservice teachers are drawn into both physics and teaching by the experience of first taking University Physics (the transformed introductory course), then helping teach the course as learning assistants. Stewart reaches out proactively to every individual with an interest in or talent for physics - and in her eyes many students have that interest or talent. She rarely directly promoted physics teaching with a student; it is simply one of the possible career outcomes available, treated equally with the other options. Students who find that they enjoy physics, but do not want to go into physics research, decide that physics teaching is a good fit as well as a reliable career choice. They report that what led them to consider teaching as a career is Stewart's high esteem for the profession. Once a student expresses an interest in teaching, proactive advising is extremely significant for recruitment. Stewart helped students navigate program requirements, advocated for qualified individuals, and cut through red tape on students' behalf. With her energetic investment in each student's success, she embodied UArk's "Students First" motto.

\section{Champion and institutional commitment}

Stewart exemplifies the concept of a champion of physics teacher education, defined in this study as one who secures personnel and funding in support of physics teacher education. Over the years, Stewart enjoyed a mandate to devote a significant fraction of time to physics teacher education. Her funding success and national recognition (both primarily for physics teacher education) motivated the UArk administration to support her through promotion and institutional funding.

Stewart cultivated UArk's institutional commitment to physics teacher education by building strong relationships with administrators, making sure they understood the benefit that accrued to UArk through her efforts, and making time to serve their interests by representing UArk at regional events. UArk administrators understand themselves as having to work against the perception (by the public and by the state legislature) that universities are "gloriously useless," in the words of an Associate Dean of Arts and Sciences. Institutional buy-in to physics teacher education is attributed to the sense that physics teacher education is practical: It is a means by which the university prepares students for jobs of recognized value, and thus serves the community. The PhysTEC award is seen as having been the beginning of a new era for UArk: the Associate Dean quoted above said, "It changed everything," referring primarily to the university's image in the community. Physics teacher education at UArk directly serves state interests in that UArk graduates are leading the establishment of STEM-focused high schools recently initiated by the governor. In this context, the success of the UAteach program, which has recruited 71 students in its first year (140\% of the most optimistic estimate), is a major public-relations success for the institution. Stewart is also significant in a public relations sense: the Provost and Vice Chancellor for Academic Affairs recognizes her as a "nationally known charismatic leader who excites students," improves UArk's reputation, and proves her worth by securing external funding (one of the most successful fundraisers at the institution). The Provost's support of UAteach is motivated in large part by Stewart's national recognition and proven track record of obtaining external funding. Overall, the political relevance of physics teacher education and Stewart's mutually beneficial relationships with administrators have been very important to the long-term success of physics teacher education at UArk.

Future physics teachers at UArk speak movingly about having learned (in University Physics or elsewhere) that everyone can learn physics; as teachers, they hope to bring out that potential in students. Arkansas's rural poverty is both a challenge and an inspiration: teacher candidates hope to show Arkansan children and their parents that in spite of expectations to the contrary, they can succeed academically, even in science. Though recruitment has in the past been sustained primarily by Stewart's activity, the reasons motivating students to go into physics teaching are bigger than Stewart, and can be expected to continue to motivate students in the foreseeable future.

\section{B. University of Colorado, Boulder}

The University of Colorado, Boulder (CU-B) is a large research institution nationally known for overall excellence in STEM education. CU-B is a site that relishes growth and prioritizes institutionalization of programs. Institutional commitment to physics teacher education at CU-B is substantial, though it may take the form of commitments to STEM education improvements that benefit physics teacher education indirectly. 


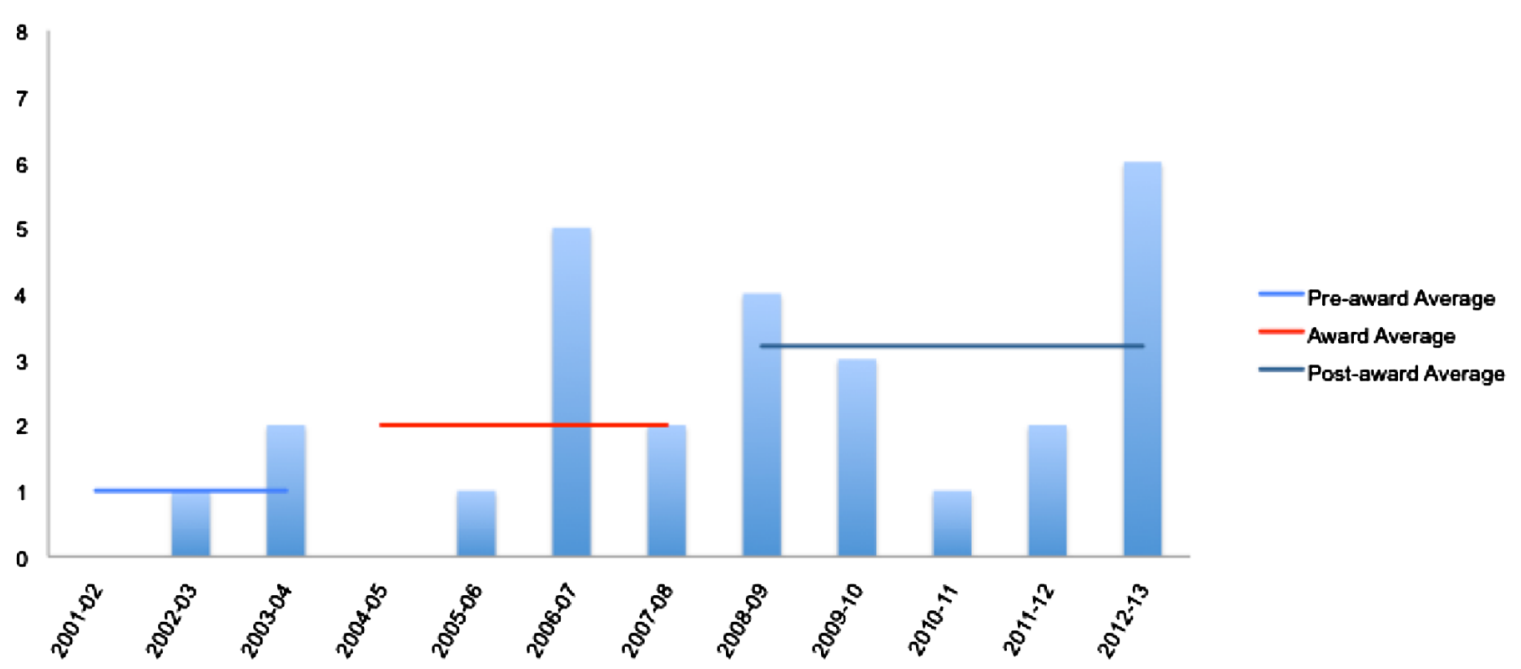

FIG. 4. PhysTEC secondary graduates from the University of Colorado, Boulder (CU-B).

The number of PhysTEC Secondary Graduates averaged one per year in the pre-award period, increased to an average of two per year during the award (2004-2008), and increased further to about three per year in the 5 years after the award period (Fig. 4). Lessons learned from CU-B about sustaining physics teacher education programs in the PhysTEC model are listed in Fig. 5.

\section{Institutional strength: Learning Assistants}

CU-B's LA program, created concurrently with PhysTEC funding, is a centerpiece of its teacher education program. The LA program as a whole is very large, with 100-150 LAs participating from about a dozen departments every year. The program is a national model; universities and colleges around the country benefit from CU-B's dissemination of LA resources and expertise. LAs take a campus-wide, one-semester pedagogy course taught by one of the LA Program Directors, a Teacher in Residence, and/ or a senior graduate student. The physics LA program is the main mechanism for course transformation and the primary source for recruiting future physics teachers. Physics hires thirty to forty LAs each year in a competitive application process. Though most of these LAs are in the introductory courses, an increasing number of upper-division courses also benefit from LA support. Faculty members who partner with LAs to transform their courses are more likely to recognize the value of teaching, and therefore the appropriateness of teaching as a career for physics majors. Physics LAs who want to become teachers have access to several physics faculty members who support careers in physics teaching and will direct them to appropriate faculty in the School of Education, such as Valerie Otero, who cofounded the LA program with now-emeritus faculty member Dick McCray.

CU-B has a large network of people who contribute to the physics LA program and physics teacher education broadly construed. Physics faculty member Steve Pollock recruits students to be LAs by making announcements in physics classes and communicating with undergraduate advisors, interviews LA applicants, recruits faculty to consider applying for LA support, mentors faculty in applying for LA support for their courses, matches LAs with faculty, mentors faculty in making good use of LAs once they have them, and keeps an archive of resources for LA-supported courses that make it easier for faculty to offer quality LA preparation and course materials. Associate Chair Michael Dubson and Science Education Initiative (SEI) Director Katherine Perkins also assist with LA administration, and there is good buy-in from the departmental faculty and administration. LA co-director Laurie Langdon co-creates and maintains physics-specific pedagogy classes for LAs and promotes secondary physics teacher education in the context of LA development. Physics faculty member Dubson creates departmental pathways for physics teaching; science education faculty member Erin Furtak teaches, advises, and mentors physics teachers; and longtime Teacher in Residence

- Elements of a physics teacher education program can be sustained as part of an overall program of excellence in STEM education.

- The presence of a physics education research group can significantly advance and sustain activities supporting physics teacher education, including course transformation, Learning Assistants (LAs), and courses on the teaching and learning of physics. These items are also well aligned with department priorities.

- Support and recognition of champions depends significantly on departmental incentives for faculty to support physics teacher education. Departmental priority for physics teacher education depends, in turn, on institutional incentives. Without these in place, champions are likely to put their efforts elsewhere.

FIG. 5. Lessons learned from the University of Colorado, Boulder (CU-B) about sustaining physics teacher education programs in the PhysTEC model. 
Steve Iona teaches LA pedagogy classes and advises preservice secondary physics teachers. Overall, the CU-B LA program is a large, diverse, and thriving community focused on teaching and learning.

About 13\% of LAs go on to be teachers [23]. In the early days of the LA program, this successful recruitment may have been attributable primarily to Otero, who compellingly advised many students to enter the teaching profession. However, physics teacher recruitment and education at CU-B has continued to increase even as Otero's focus has moved to supporting inservice teachers.

\section{Champions and institutional commitment}

Otero, Pollock, and Finkelstein have championed physics teacher education at CU-B for many years by securing funding and staff and negotiating with the institution for programs benefiting physics teacher education. In recent years, their effort has broadened to building excellence in STEM education more comprehensively, aligned with institutional priorities. Otero and Finkelstein are leaders in establishing the (Provost-funded) Center for STEM Learning, whose mission includes the promotion of "K-20 faculty recruitment, preparation, and professional development," among many other goals. Otero is well recognized both locally and nationally for her leadership of the LA program; she also directs the Colorado Noyce Fellowship program (a scholarship program for future teachers), co-directs the $\mathrm{CU}$ Teach program (a replication of UTeach), serves on the National Task Force for Teacher Education in Physics [2], and promotes physics teacher education through published studies of teacher knowledge and practice and through hundreds of invited talks around the country and around the world. Finkelstein conducts research on teacher education, develops numerous programs to strengthen the teaching identity of the physics department, and engages at a policy level, including testifying before the U.S. Congress on the state of STEM education at the undergraduate and graduate levels and contributing to the efforts of the Association of Public and Land-Grant Universities (APLU) in the Science and Mathematics Teacher Imperative [21]. Otero, Pollock, and Finkelstein have all been supported with promotion, awards, and institutional funding for programs.

Institutional commitment to physics teacher education at CU-B is substantial, though it sometimes takes the form of commitments to STEM education improvements that benefit physics teacher education only indirectly. For example, the LA program, which was initially supported by grant funding, is now funded significantly by the Provost, who is motivated by the program's effectiveness in course transformation and teacher recruitment. Many STEM departments at CU-B, including physics, invest significantly in course transformation: The physics department accepts physics education research (PER) faculty as full colleagues as part of its long-term commitment to research-based improvement of instruction, and the physics chair brings a bag of clickers on recruitment visits to demonstrate interactive engagement to prospective students and their parents. The establishment of the Center for STEM Learning, which houses STEM education research awards and seeks to create STEM education faculty lines to be shared with disciplinary departments, may benefit physics teacher education by supporting and stabilizing constituent programs such as Streamline to Mastery (a teacher scholarship program supporting inservice teacher development). The CU Teach program involves significant commitment to STEM teacher education by the institution, especially the School of Education, but physics teacher education is not yet a strong part of that program.

Over the years departmental, institutional, and intellectual pressures have reduced the effort that lead faculty dedicate to the physics teacher recruitment that PhysTEC emphasizes. The physics department places a high value on course transformation, but does not specifically support Finkelstein and Pollock in championing physics teacher education. Since 2009, Otero has focused significant attention on Streamline to Mastery and other programs intended to support inservice teachers that were recruited through the LA model; as her support of inservice teachers recruited through the LA model has increased, her one-on-one recruitment of LAs into physics teaching has decreased. Though Finkelstein, Pollock, and Otero all continue to significantly benefit physics teacher education, none of them experience their PhysTEC champion role as their top priority.

\section{Florida International University}

Florida International University (FIU) is a young university making a significant investment in STEM education. FIU's youth, its origins as a two-year upper-division university, its strength in the sciences, and its search for a community-minded and forward-looking identity all contributed to its ready acceptance of the PhysTEC reforms and initiatives. Through shared program development and effective fundraising, the site leaders have secured their reputations, both on campus and nationally.

The numbers of PhysTEC secondary graduates are increasing, from zero teachers in the pre-award period to one per year in the award period and an average of two per year since the award (see Fig. 6). Lessons learned from FIU about sustaining physics teacher education programs in the PhysTEC model are listed in Fig. .7

\section{Institutional strength: Course transformation}

FIU's distinctive mechanism of teacher education centers on Modeling Instruction, a widely disseminated program of high school physics instruction that FIU has adapted for university courses. Modeling Instruction is joined in the physics department by Open Source Tutorials [24,25], which are used in some physics labs, and the 


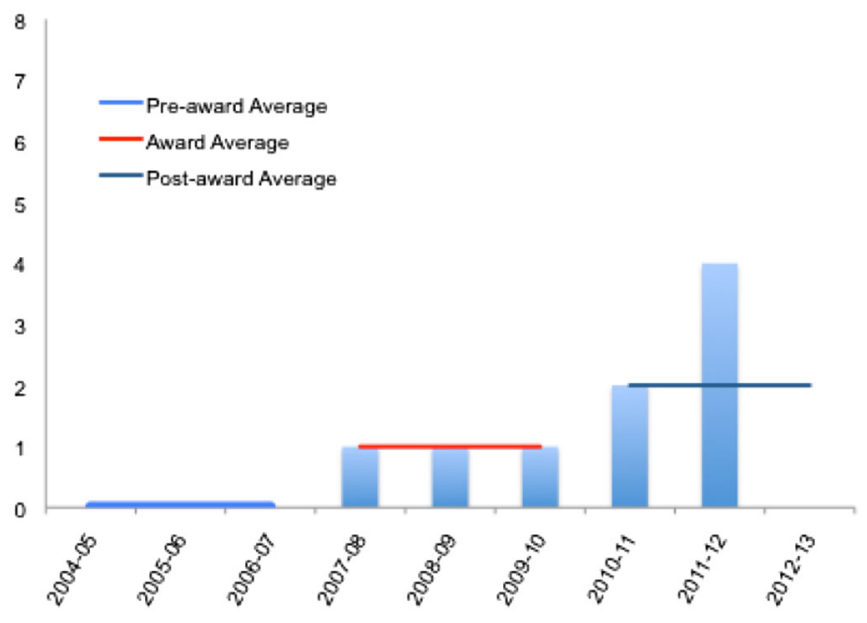

FIG. 6. PhysTEC secondary graduates from Florida International University (FIU).

Investigative Science Learning Environment (ISLE), another best-practices instructional format introduced to FIU more recently. Physics course transformation at FIU is both nationally admired and locally appreciated; most consider it responsible for FIU's extraordinary increase in the number of physics majors, as well as respectable output of high school physics teachers. Students and faculty believe the transformed courses are especially powerful for first-generation college students and others who may assume they would not succeed in physics. The Physics LA program is a primary mechanism for physics course transformation and a primary source for the recruitment of future physics teachers. Modeling Instruction demonstrates to students that they can do physics; the LA program convinces them that they can teach physics. Finally, role models offer students a practical vision of a teaching career: Physics teacher education at FIU is

- STEM education, and by extension physics teacher education, are potentially institution-defining interests.

- Major sustained and even increasing institutional support for physics teacher education is possible. PhysTEC can play a significant role in precipitating such institutional commitment.

- Program changes can align with institutional priorities to generate significant rewards.

- A multidisciplinary STEM education research effort can leverage internal resources.

- Sites can sustain Teachers in Residence through teaching and staff positions relate $\mathrm{d}$ to teacher education.

- A physics education research group can significantly advance and sustain physics teacher education program components, including course transformation, LAs, and courses on the teaching and learning of physics. These changes align well with department priorities.

FIG. 7. Lessons learned from Florida International University (FIU) about sustaining physics teacher education programs in the PhysTEC model. significantly supported by very active Teachers in Residence who have continual substantive contact with undergraduates who might have an interest in teaching, as well as preservice and inservice physics teachers.

\section{Champions and institutional commitment}

High-quality teaching, student learning, innovation, and collaboration all feature prominently in FIU's mission statement. PhysTEC catalyzed interest in physics teacher education, especially during site visits in which PhysTEC leaders met with FIU administrators. The FIU Physics Education Research Group, engagement in the Science and Mathematics Teaching Imperative [21], and partnership with a national network for educating science and math teachers [26] solidified institutional participation.

The first PhysTEC-funded Teacher in Residence, Leanne Wells, a former lead teacher for an FIU-based high school STEM immersion program, was recruited to help design new math and science teacher education programs in the College of Arts \& Sciences when severe budget cuts motivated the state of Florida to close all of the secondary education teacher preparation programs in the College of Education. (This transition was significantly facilitated by PhysTEC-oriented conversations with FIU administration.) Wells has since been retained by the College of Arts \& Sciences as the coordinator for the Science and Mathematics Teaching Imperative [21]. From an office centrally located in FIU's Physics Learning Center, the program coordinator advises and mentors preservice teachers, supports inservice teachers in maintaining connections to FIU, manages STEM teacher preparation program needs, and coordinates a professional network for student teaching and other placements. Wells is moving into the STEM Transformation Institute to direct the campus-wide LA program, and a new Teacher in Residence will replace her as secondary science program coordinator.

In 2010, at the end of the PhysTEC award period, another former Teacher in Residence (David Jones) was hired through a large physics research award to serve as an Education and Outreach Program Coordinator. In that grant-supported role, Jones has supported a local community of high school physics teachers, offered teacher professional development workshops centered on Modeling Instruction, and overseen course transformations in the Physics department. In 2012, the Physics department began supporting Jones as an instructor. His responsibilities in introductory physics place him in constant contact with undergraduates who might have an interest in teaching, and his long history as a committed, engaged teacher of high school physics is a significant inspiration to many. His centrally located office, next to Wells, positions high school physics teaching at the heart of the FIU Physics Learning Center. 
Institutional commitment continues to increase as partnerships with school districts begin to bear fruit. Discussions at the Dean and Provost levels confirm that FIU regards physics education as a cornerstone of its STEM achievements so far, and looks to physics education faculty as major stakeholders in future growth and development. FIU established the STEM Transformation Institute, intended to bring together faculty from FIU's College of Arts \& Sciences, College of Education, and College of Engineering and Computing in a collective mission to transform STEM education from preschool to graduate school. The Institute enjoys extremely strong University support at the Dean, Provost, and Presidential levels; it has a name, an infrastructure, a director (PhysTEC site leader Laird Kramer), and an initial budget of $\$ 700,000$ for the first 3 years. Physical spaces for Institute operations opened in 2013. The Institute will house STEM Education research awards and will create STEM Education faculty positions that will be shared between the Institute and the disciplinary science departments. Departments that wish to take advantage of this opportunity will need to decide how to evaluate STEM education faculty for tenure and promotion, a process which is likely to initiate challenging negotiations within and between departments. These challenges, however, have the potential to increase the value that disciplinary departments place on STEM education, and the value that the physics department places on physics teacher education.

Among the FIU faculty, PhysTEC site leader Kramer is the primary "dealmaker," initiating a wide array of funding proposals, internal agreements, and external collaborations, often working closely with FIU administration for mutual benefit. Kramer's leadership is recognized with his appointment to direct the STEM Transformation Institute. Faculty member Eric Brewe is the local expert in Modeling Instruction (a guided-inquiry interactive-engagement method of physics teaching), the primary physics education research advisor, and teaches upper-division teacher education courses; he has an appointment in the College of Education and is an affiliate in the physics department [27]. Kramer and Brewe have a history of shared program development and funding that has secured their reputations on campus and nationally. Both have been supported at FIU with promotion, hiring of new STEM education colleagues, and institutional funding for programs such as the LA program and the STEM Transformation Institute.

FIU has a large and thriving team contributing to physics teacher education, including faculty, Teachers in Residence, a postdoc, and graduate student researchers at the time of the study. These university personnel are at the hub of an extensive network of learning assistants, preservice teachers, and inservice teachers that enliven the hallways of the physics department. Two highly qualified and very active Teachers in Residence, centrally positioned in the physics department, support preservice and inservice physics teachers and inspire LAs to consider the teaching profession. Graduate student and postdoctoral researchers conducting high-quality investigations into teaching strategies, physics course transformation, and learning assistant development contribute to the knowledge base and promote FIU's programs to the physics education research community.

\section{Seattle Pacific University}

Seattle Pacific University (SPU) is a private liberal arts university whose physics faculty share a deep commitment to physics teacher education: For over a decade, every person hired into the physics department has had a teaching and learning priority. Institutional support for physics teacher education is credited to alignment with the mission of the university and with SPU's historic basis in teacher education. The average number of PhysTEC secondary graduates increased from about 2.5 per year in the preaward period to 3 during the award period (2006-2009), and then to about 4 per year since the award (see Fig. 8), an especially impressive result for such a small institution (3000 undergraduates). Lessons learned from SPU about sustaining physics teacher education programs in the PhysTEC model are listed in Fig. 9.

\section{Institutional strength: Departmental focus on physics education}

SPU's physics department decided a decade ago to make physics education its focus as a means of reviving a department at risk and aligning with the university's emphasis on teaching and service. Since that time, every person hired into the physics department has had a teaching and learning priority. The majority of departmental faculty champion physics teacher education by dedicating substantial time and effort to recruitment, physics-specific pedagogy and methods courses, STEM teacher education program development, and research on teacher learning. Because SPU is a small institution where interpersonal agreements can often take the place of formally negotiated policies, faculty members are relatively free to develop programs and activities that suit their priorities.

An example of departmental focus on teaching and learning is SPU's physics LA program, which began with the purpose of supporting introductory course transformation, and was shaped by SPU faculty into a significant experience in its own right. Faculty LA supervisors have had a strong policy of inclusion in order to have a critical mass of LAs working together: Supervisors are not only flexible about logistics but also promote the program as valuable preparation for medical school entrance exams (in that it deepens content knowledge) and preparation for medical professionals (in that teaching and medicine both involve listening for the purpose of diagnosis). The program has been marked by innovative activities such as 


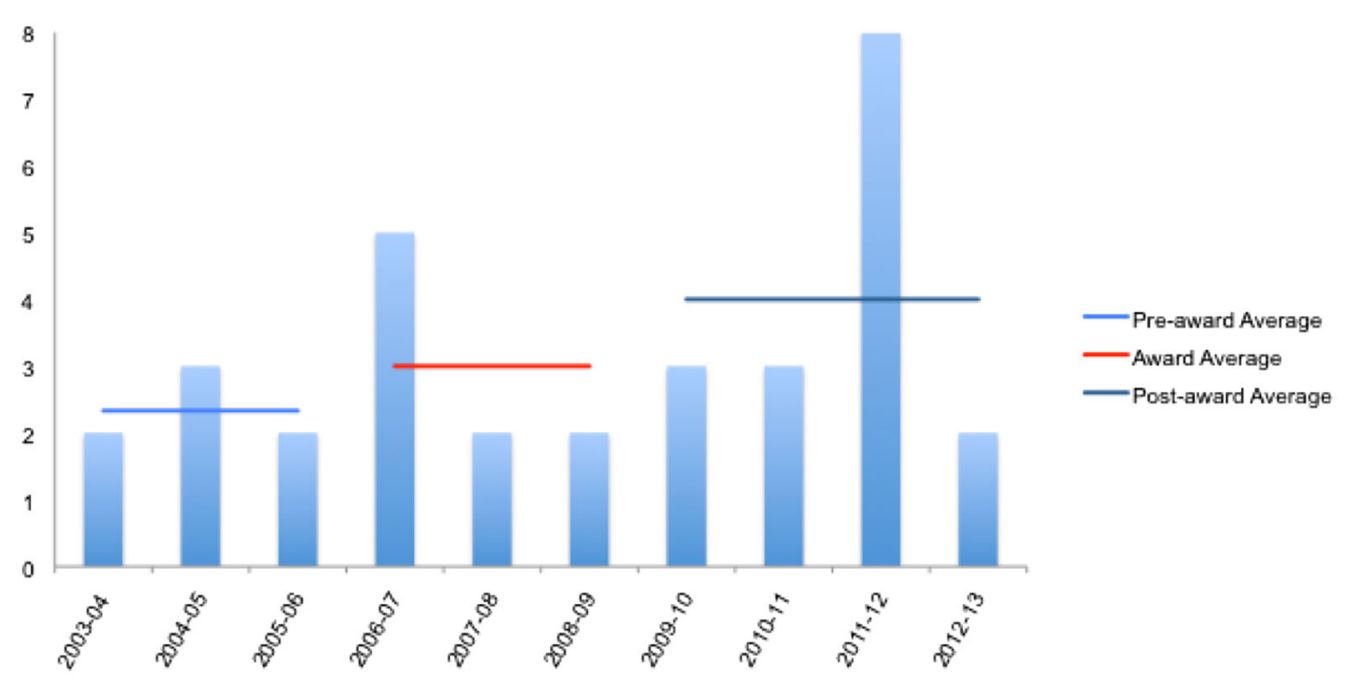

FIG. 8. PhysTEC secondary graduates from Seattle Pacific University (SPU).

having LAs interview a peer about a physics concept with the goal of only finding out about their thinking, not "teaching" anything. Such activities are especially appropriate in the SPU student culture, which is strongly service oriented and particularly values service in the context of deep interpersonal encounter.

LAs who have become secondary teachers credit teacher scholarships (especially Robert Noyce Teacher Scholarships) and faculty mentorship as particularly significant to their decision. The LA program continues to grow and retains many of the features that were originally significant, including bonding with a cohort of fellow LAs, being entrusted to co-design their pedagogy experience, admiring faculty who are visibly dedicated to a continuum of physics teacher professional development, being valued as junior educators by those faculty, and being supported in and celebrated for applying for teacher scholarships.

\section{Champion and institutional commitment}

Administrators at the Dean, Provost, and President level visibly support the physics department's efforts benefiting physics teacher education, seeing them as well aligned with the mission of the university ("Engage the Culture,

- Small institutions can educate large numbers of PhysTEC graduates.

- A team dedicated to physics teacher education enables programs to continue even as personnel may change.

- A physics department can successfully shape its mission around physics teacher education, putting considerable resources toward teacher recruitment and preparation without sacrifice to its undergraduate program.

FIG. 9. Lessons learned from Seattle Pacific University (SPU) about sustaining physics teacher education programs in the PhysTEC model.
Change the World") and consistent with SPU's long history in teacher education (SPU's predecessor institution was originally a normal school for teacher training). At the presidential level, excellence in physics teacher education is seen as contributing to SPU's distinction as a Christian college excelling in science. Physics department accomplishments related to physics teacher education are featured at the annual faculty retreat, in the State of the University address, on the SPU website, and in SPU's alumni magazine. A passionate alumna of the LA program serves as the honorary young alumna on the Board of Trustees. Support for physics department efforts is evident in the expansion of the physics department from two faculty members to six in about 10 years.

The physics LA program is the subject of great attention from the university administration, which admires the program for improving undergraduate education in a cost-effective manner, transforming faculty practices, creating community among students, and improving the image and national reputation of the university. At the provost and dean level, the LA program is particularly valued for improving undergraduate student learning, but the "mission fit" of physics teacher education is acknowledged there as well. The university is establishing a campus-wide LA program, funded by the institution and co-led by the physics department and the Center for Scholarship and Faculty Development.

Physics teacher education at SPU is the outcome of efforts of a team of champions. Two of the most senior faculty members in this small department (Stamatis Vokos [28] and Lane Seeley) were hired a decade ago for their focus on physics education and made physics teacher education a priority ever since the PhysTEC award. Seeley was PhysTEC site leader, and Vokos contributed as a significant "dealmaker," often working with national agencies and SPU administration for mutual benefit. 
The Energy Project, a \$3.7 million award to support and study teacher practices of formative assessment in the context of energy in physics (2008-2013), brought tremendous recognition to these physics department leaders on a campus not accustomed to research awards. Faculty member Eleanor Close held a joint appointment in physics and education; she was especially valued for her service efforts in both departments and contributed to significant programmatic changes benefiting secondary teacher education [29]. Faculty member Hunter Close significantly shaped the LA pedagogy course and mentored physics teacher candidates [30]. These faculty leaders have strongly influenced subsequent hiring of physics department faculty and staff supporting physics teacher education. New faculty and staff continue to secure funding for physics teacher education and negotiate with the institution for changes beneficial to physics teacher education.

Almost everyone in the physics department at SPU is significantly engaged in activities directly benefiting physics teacher education. Faculty, staff, the Teacher in Residence, and graduate researchers cultivate mutually beneficial relationships with educators all along the continuum of a teaching career, from undergraduates interested in teaching to experienced inservice teachers. On the faculty team, Amy Robertson and Kara Gray have continued to develop the innovative LA program established by Vokos, Seeley, and department chair John Lindberg and significantly developed by Hunter Close. Lezlie DeWater, SPU's Teacher in Residence since 2004, mainly serves elementary teachers, but also advises preservice secondary teachers and teaches physics-specific pedagogy courses; two Visiting Master Teachers mentor future teachers on a part-time basis. Scherr, a faculty-level researcher, promotes physics teacher education with presentations and publications focused on teachers' content understanding of energy in physics. A national and international network of collaborators has contributed to the group's research and teaching efforts through the Interdisciplinary Research Institute in STEM Education (I-RISE), an intensive summer internship program through which scholars from diverse backgrounds gather to observe, document, and reflect on professional development courses offered by the Energy Project.

\section{IMPLICATIONS FOR PHYSICS TEACHER EDUCATION PROGRAMS USING THE PHYSTEC MODEL}

The purpose of this study is to inspire and support institutions in building thriving physics teacher education programs of their own by sharing the mechanisms by which other successful institutions use the PhysTEC model to educate increasing numbers of new highly qualified physics teachers. In this model, institutions play to their strengths: they take advantage of existing programs, personnel expertise, political conditions, and so on to increase the number of highly qualified physics teachers educated over the long term. The diverse implementations of PhysTEC key components in the thriving physics teacher education programs described in this study illustrate the variety of ways that different institutions have successfully cultivated physics teacher education programs.

The finding that most PhysTEC legacy sites have sustained increases in the number of highly qualified physics teachers educated per year over the long term suggests that the PhysTEC model is effective for this purpose. The finding that all studied sites that invested in physics teacher preparation sustained an increase in the number of physics teachers educated per year (and sites with a greater investment saw greater increases in their long-term number of physics teachers educated) is evidence of a strong relationship between funding for physics teacher preparation and the number of physics teachers educated per year. Funding for physics teacher preparation often provides benefit that goes beyond educating more physics teachers, frequently supporting activities for all preservice teachers at an institution, or both inservice and preservice teachers, or the undergraduate physics program as a whole. Finally, the identification of two features common to sustained physics teacher preparation programs-a champion of physics teacher education and institutional commitment - suggests clear pathways to establishing and sustaining programs at other institutions. A functional definition of a champion (as one who secures funding and personnel benefiting physics teacher education and negotiates with the institution for changes beneficial to physics teacher education) may help institutions identify and support personnel in key roles, especially as they recognize that institutional support for the champion(s) and the program are crucial for sustaining efforts supporting physics teacher preparation.

\section{ACKNOWLEDGMENTS}

This material is based upon work supported by National Science Foundation Grants No. 0808790, No. 0108787, and No. 0833210. We gratefully acknowledge the contribution of PhysTEC site leaders at all the studied institutions, including E. Brewe, N. Finkelstein, C. Henderson, L. Kramer, L. McNeil, I. Novodvorsky, V. Otero, L. Seeley, G. Stewart, and S. Vokos. 
[1] PhysTEC is a project of the American Physical Society and the American Association of Physics Teachers.

[2] D. E. Meltzer, M. Plisch, and S. Vokos, Transforming the Preparation of Physics Teachers: A Call to Action. A Report by the Task Force on Teacher Education in Physics (T-TEP) (American Physical Society, College Park, MD, 2012).

[3] The first PhysTEC sites launched in 2001 were funded for 5 years; after this, the project switched to a funding period of 3 years.

[4] PhysTEC "legacy sites" are PhysTEC sites whose award period has ended.

[5] R. E. Scherr, M. Plisch, and R. M. Goertzen, Sustaining programs in physics teacher education: A study of PhysTEC supported sites (American Physical Society, College Park, MD, 2014).

[6] S. M. Wilson, R. E. Floden, and J. Ferrini-Mundy, Teacher preparation research: Current knowledge, gaps, and recommendations (Center for the Study of Teaching and Policy, University of Washington, Seattle, 2001).

[7] National Research Council, Preparing teachers: Building evidence for sound policy (National Academy Press, Washington, DC, 2010).

[8] M. Allen, Eight questions on teacher preparation: What does the research say? A summary of the findings (Education Commission of the States, Denver, CO, 2003).

[9] L. Darling-Hammond and J. Bransford, Preparing teachers for a changing world (National Academy of Education, Washington, DC, 2005).

[10] Studying teacher education: The report of the AERA panel on research and teacher education (Routledge, New York, 2009).

[11] B. C. Clewell, K. Darke, T. Davis-Googe, L. Forcier, and S. Manes, Literature Review on Teacher Recruitment Programs (The Urban Institute, Washington, DC, 2000).

[12] D. J. Boyd, P. L. Grossman, H. Lankford, S. Loeb, and J. Wyckoff, Teacher preparation and student achievement, Educ. Eval. Policy Anal. 31, 416 (2009).

[13] M. Cochran-Smith, M. Cannady, K. P. McEachern, P. Piazza, C. Power, and A. Ryan, Teachers' education, practice, and retention: A cross-genre review of recent research, J. Educ. 191, 19 (2000).
[14] S. Vokos and T. Hodapp, Characteristics of thriving physics teacher education programs, in Recruiting and Educating Future Physics Teachers: Case Studies and Effective Practices, edited by C. Sandifer and E. Brewe (American Physical Society, College Park, MD, 2015).

[15] http://phystec.org.

[16] For more information about the UTeach program, see Ref. [17]. Fewer than $3 \%$ of UTeach graduates are physics majors [18].

[17] http://uteach.utexas.edu.

[18] M. Marder (private communication).

[19] PhysTEC institutions endorse the APS Joint Statement on the Education of Future Teachers. For a current list of PhysTEC institutions see Ref. [20].

[20] A current list of PhysTEC institutions is available at http://www.phystec.org/institutions/.

[21] Association of Public and Land-Grant Universities, Science and Mathematics Teaching Imperative, 2016, available from http://www.aplu.org/projects-and-initiatives/stem-education/ science-and-mathematics-teaching-imperative/.

[22] Stewart moved to West Virginia University in 2014.

[23] V. Otero, S. Pollock, and N. Finkelstein, A physics department's role in preparing physics teachers: The Colorado learning assistant model, Am. J. Phys. 78, 1218 (2016).

[24] R. E. Scherr and A. Elby, Enabling informed adaptation of reformed instructional materials, AIP Conf. Proc. 883, 46 (2007).

[25] R. E. Scherr, A. Elby. R. M. Goertzen, and L. D. Conlin, Open Source Tutorials in Physics Sensemaking: Suite II, 2010, available from http://www.spu.edu/depts/physics/ tcp/tadevelopment.asp.

[26] 100Kin10. 100Kin10: Enriching America's classrooms with 100,000 more excellent STEM teachers by 2021, 2016; available from https://100kin10.org/.

[27] Brewe moved to Drexel University in 2017.

[28] Vokos moved to California Polytechnic University, San Luis Obispo in 2016.

[29] E. Close moved to Texas State University in 2011.

[30] H. Close moved to Texas State University in 2011. 